\title{
Evaluation of Efficacy and Toxicity of Treatment Using Rhenium-186 HEDP in Metastatic Bone Disease
}

\author{
Gaber Ziada $^{a}$ Lila Faris $^{\mathrm{b}}$ Shreif Yacoub ${ }^{\mathrm{b}}$ Abdelhamid Elgazzar ${ }^{\mathrm{a}}$ \\ aDepartment of Nuclear Medicine, Faculty of Medicine, Kuwait University, Kuwait; \\ bDepartment of Radiotherapy, Faculty of Medicine, Ain-Shams University, Cairo, Egypt
}

\section{Key Words}

Rhenium-186 HEDP . Palliation of metastatic bone disease

\begin{abstract}
Objective: To assess the efficacy and toxicity of rhenium-186 HEDP in treating metastases. Patients: Twenty-six patients with bone pain from metastatic cancer were treated with $35 \mathrm{mCi}$ of ${ }^{186} \mathrm{Re}$ HEDP administered intravenously in the outpatient clinic. Methods: Patients were followed with pain diaries, records of medication, morbidity, sleep patterns, serial bone scans and a Karnofsky index. Twenty-five patients with complete records were evaluated. Patients were grouped according to the extent of bone metastases as seen in the bone scans. Results: Sixteen patients (64\%) showed clinical responses of which 4 became completely painfree. Pain relief typically began 10-20 days after ${ }^{186}$ Re HEDP was administered, while maximum benefit was normally achieved by
\end{abstract}

\begin{tabular}{ll}
\hline KARGER & (1) 1999 S. Karger AG, Basel \\
Fax +4161306 1234 $34-7571 / 99 / 0083-0196 \$ 17.50 / 0$ \\
$\begin{array}{l}\text { E-Mail karger@karger.ch } \\
\text { www.karger.com }\end{array}$ & $\begin{array}{l}\text { Accessible online at: } \\
\text { http://BioMedNet.com/karger }\end{array}$
\end{tabular}

6 weeks. Relief of pain was maintained for 415 months (mean 6 months). No immediate adverse reactions were observed following the administration of ${ }^{186}$ Re HEDP. Only a mild transient fall in platelet levels was noted, which normalized by 6 weeks. Conclusion: ${ }^{186}$ RE HEDP appears as a safe, convenient and an effective palliative for pain secondary to bone metastases in cancer patients.

\section{Introduction}

The control of bone pain in patients with multiple skeletal metastases to improve the quality of life is a significant clinical problem. Bone pain, confined to a single site, usually responds to local external radiation beam therapy. Hemibody irradiation can be used to control multifocal pain, but has the disadvantage of significant morbidity. Hormone treatment and chemotherapy are often effective at the onset of the disease $[1,2]$.

\section{Dr. Gaber Ziada}

Department of Nuclear Medicine

Faculty of Medicine, Kuwait University

PO Box 24923

13110 Safat (Kuwait) 
Table 1. Pretreatment characteristics of patients who received ${ }^{186} \mathrm{Re}$ HEDP

\begin{tabular}{lc}
\hline Characteristic & \\
\hline Age, years $^{\mathrm{a}}$ & $58(48-78)$ \\
Performance status - Karnofsky index $^{\mathrm{b}}$ & $72.3 \pm 2.07$ \\
Hematology - Hemoglobin, g/dl & $12.0(7.5-14.4)$ \\
$\quad$ Platelets, $10^{9} / 1$ & $288(116-602)$ \\
$\quad$ TLC, $10^{9} / 1$ & $4.1(3.8-1.3)$ \\
Percent of patients receiving strong opiates & 43.9 \\
\hline a Median and range. & \\
b Mean \pm ISE. & \\
\hline
\end{tabular}

Although morphine-based analgesics are clearly effective in intense pain, there are considerable side effects. In addition, it is a costly treatment when large doses have to be administered over a long period of time. The cost of repeated radiotherapy is also considerable $[3,4]$.

The application of bone-seeking radiopharmaceuticals which concentrate at sites of increased bone turnover is promising, and is an important alternative for hemibody or whole-body radiotherapy [5-7]. Maxon et al. $[8,9]$ demonstrated the favorable biodistribution and dosimetry of rhenium-186 HEDP with tumor/marrow dose ratios that were higher than those achieved with ${ }^{89} \mathrm{Sr}$-chloride, and the resultant relief of pain without significant bone marrow toxicity [9].

The main objectives of this study are to assess the efficacy and toxicity of ${ }^{186}$ Re HEDP in treating bone pain secondary to metastases.

\section{Patients and Methods}

Twenty-six patients with multiple site painful bone metastases treated with ${ }^{186}$ Re HEDP were included, 12 with prostatic cancer, 10 with breast cancer, 2 with colon cancer and 2 with lung cancer. Twenty-five patients with complete records were retrospectively evaluated.
The criteria for inclusion were life expectancy of more than 3 months, adequate hematological function (leukocytes $>3 \times 10^{9} / 1$; platelet $>100 \times 10^{9} / 1$ ) and no change in systemic anticancer therapy over the last 3 months, recent bone scan, and an informed consent. Table 1 summarizes patient's data.

At the entry of the study a clinical examination was performed. A review of the patient's pain, analgesic intake, morbidity and performance (Karnofsky scale) were also conducted. The patient was asked to keep a diary of these parameters for 7 days prior to treatment. Patients were grouped according to the extent of metastases as having light, moderate, extensive or superscan pattern of metastases. A dose of $35 \mathrm{mCi}{ }^{186} \mathrm{Re}$ HEDP treatment was given intravenously via simple saline drip, and bone scans utilizing the ${ }^{186}$ Re HEDP were obtained after $2 \mathrm{~h}$.

After the treatment, patients continued to complete their daily diaries. A full blood count and biochemical profile were obtained at 4,8 and 12 weeks and a bone scan was repeated at the time of the final assessment at 12 weeks.

Response to therapy was defined as follows: Complete response: patient becomes pain-free with no analgesic requirements and a significant improvement in morbidity and Karnofsky index. Partial response: patient shows significant reduction in analgesic requirement, and significant improvement in Karnofsky scale and morbidity. No response: no change or increase in analgesic requirement, and deterioration of morbidity and Karnofsky scale. Assessment of hematological toxicity was done according to the RTOG criteria to classify platelet toxicity into: grade $1(75,000-$ $100,000)$, grade $2(50,000-75,000)$, grade $3(25,000-$ $50,000)$, and grade $4(<25,000$ or spontaneous bleeding). 
Table 2. Assessable patients treated with ${ }^{186}$ Re HEDP at a dose of $35 \mathrm{mCi}$ categorized by response and extent of bone metastases

\begin{tabular}{lllll}
\hline Response & \multicolumn{4}{l}{ Extent of metastases } \\
\cline { 2 - 5 } & light & moderate & extensive & superscan \\
\hline Complete response & $3(60 \%)$ & $1(11 \%)$ & & \\
Partial response & $2(40 \%)$ & $7(78 \%)$ & $2(40 \%)$ & $1(17 \%)$ \\
No response & & $1(11 \%)$ & $2(40 \%)$ & $3(50 \%)$ \\
Progression & & & $1(20 \%)$ & $2(33 \%)$ \\
\hline
\end{tabular}

Extent of metastases was measured in a controlled fashion from skeletal MDP images. Scores were converted into the four groups named above.
Table 3. Response of painful osseous metastases to repeat doses of ${ }^{186}$ Re HEDP therapy

\begin{tabular}{lll}
\hline Patients & $\begin{array}{l}\text { Partial } \\
\text { responders }\end{array}$ & $\begin{array}{l}\text { Complete } \\
\text { responders }\end{array}$ \\
\hline $6(2$ injections $)$ & 2 & 4 \\
1 (3 injections) & 1 & - \\
1 (4 injections) & 1 & - \\
\hline
\end{tabular}

\section{Results}

Five patients had light metastases, 9 moderate, 5 extensive, and 6 diffuse metastases. The overall clinical response in evaluated patients was 16/25 (64\%) of which 4/25 (16\%) became effectively pain-free (table 2 ).

Pain relief began typically between 10 and 20 days after ${ }^{186}$ Re HEDP administration, and maximum benefit was achieved by 6 weeks. Relief of pain was maintained for 4-15 months with a mean of 6 months.

At 12 weeks after treatment isotopic bone scans generally showed little change and there was no correlation between the change in bone image and clinical response. There was also no correlation between changes in any of the biochemical parameters and clinical responses. The only prognostic indicator of pos- sible significance was the extent of bone metastases.

No immediate adverse reactions to the administration of ${ }^{186}$ Re HEDP were observed. A fall in platelet levels was seen in most patients with the nadir occurring about 1-2 weeks after treatment, with normalization by 6 weeks. Eight patients were treated again for recurrence of pain, for whom side effects such as a moderate decrease of platelets or an increase of pain for 1-2 days (flare-up effect) were observed. In all patients the same dose of ${ }^{186}$ Re HEDP was used for successive treatments as was used for the initial treatment with an interval of not less than 3 months. There were obvious improvement responses to the additional treatments (table 3 ).

\section{Discussion}

The present study clarifies some of the potential uses of ${ }^{186}$ Re HEDP in the palliation of painful bone metastases. So far, the experience with ${ }^{186} \mathrm{Re}$ HEDP is limited. Over the last few years, several studies have been carried out, all involving rather small groups, with the number of patients varying between 10 and 43 (table 4). The percentage of patients becoming free of pain ranged between 17 and 
Table 4. Palliation of painful bone metastases: results of ${ }^{186}$ Re HEDP therapy

\begin{tabular}{lllllll}
\hline Investigator & Year & $\begin{array}{l}\text { Activity } \\
\mathrm{mCi}\end{array}$ & Number & $\begin{array}{l}\text { Response } \\
\text { rate, } \%\end{array}$ & $\begin{array}{l}\% \text { of } \\
\text { responders }\end{array}$ & $\begin{array}{l}\text { Mean duration } \\
\text { weeks }\end{array}$ \\
\hline Maxon et al. [8] & 1988 & 35 & 12 & 100 & 17 & - \\
Zonnenberg et al. [11] & 1991 & $35-50$ & 10 & 90 & 50 & 5 \\
Maxon et al. [10] & 1991 & 34 & 43 & 77 & 21 & 7 \\
De Clerk et al. [12] & 1994 & $35-95$ & 11 & 55 & - & - \\
Limourise et al. [13] & 1997 & 35 & 16 & 81 & 19 & 10 \\
Schoeneich et al. [14] & 1997 & 35 & 44 & 60 & 19 & 5.5 \\
\hline
\end{tabular}

$50 \%$. The results from these studies at least matched the results obtained with strontium$89[6,8]$, thus indicating that ${ }^{186}$ Re HEDP might be a very promising and acceptable alternative to the established radiotracers.

The variation in response rate appearing from all studies maybe contributed to differences in response criteria, end point and patient selection. There was no obvious prognostic factor as to which patients benefited most from this therapy. Particular attention was paid to the extent of bone metastases. Our results show that better results were obtained in patients with fewer metastases (table 2). It appears, therefore, that there may be an advantage in using ${ }^{186}$ Re HEDP at an early stage of metastatic skeletal disease. No significant differences were observed between responders and nonresponders in terms of biochemistry profile, starting hematological parameters, toxicity or pattern of pain. There findings are in agreement with other studies $[10,11]$ which also suggest that patients with a lower metastastic burden may have a slightly improved response rate. However, no patient who fulfills our trial criteria should be excluded because of the extensive nature of his skeletal disease.

The encouraging results obtained using ${ }^{186}$ Re HEDP warrant comparison with alter- native palliative treatments. Hemibody radiotherapy has been used to relieve multifocal pain, but its benefit must be weighed against significant morbidity [12]. By comparison ${ }^{186}$ Re HEDP is well tolerated, and can be repeated.

However, some important questions still need to be addressed: the role of ${ }^{186}$ Re HEDP as an adjunct to local radiotherapy, the efficacy of single- or split-dose administration, and the optimum dose of ${ }^{186}$ Re HEDP required for the early treatment of pain, resulting in reduction in the occurrence of new painful sites.

\section{Conclusions}

We have shown that ${ }^{186} \mathrm{Re}$ HEDP is a safe and an effective palliative therapy, even in patients with previous wide-field irradiation. The treatment appears to have advantages in terms of cost, toxicity, and simplicity. We believe that our study has clearly shown a clinical role of ${ }^{186}$ Re HEDP therapy in an important group of patients. Further research to compare its benefit on survival, its use as an adjuvant therapy and in primary bone tumors has to be carried out. 


\section{References}

1 Tong D, Gillick L, Hendrickson FR: The palliation of symptomatic osseous metastases: Final results of the study by the Radiation Therapy Oncology Group. Cancer 1982;50:893899.

2 Salazar OM, Rubin P, Hendrickson FR, Komaki R, Poulter C, Newall J, Asbell S, Mohiuddin M, Van Ess J Single-doses half-doses half-body irradiation for palliation of multiple bone metastases from solid tumors: Final Radiation Therapy Oncology Group report. Cancer 1986;58:2936 .

3 Gilbert HA, Kagan AR, Nussbaum H, Rao AR, Satzman J, Chan P, Allen B, Forsythe A: Evaluation of radiation therapy for bone metastases: Pain relief and quality life. AJR Am J Roentgenol 1977;129:1095-1096.

4 Fitzpatrick PJ, Rider WD: Half body radiotherapy. Int J Radiat Oncol Biol Phys 1976;1:197-207.

5 Lewington VJ, McEwan AJ, Ackery DM, Bayly RJ, Keeling DH, Maccleod PM, Porter AT, Zivanoic MA: A prospective, randomized doubleblind crossover study to examine the efficacy of strontium- 89 in palliation in patients with advanced prostate cancer metastatic to bone. Eur J Cancer 1991;27:954-958.
6 Laing AH, Ackery DM, Bayly RJ, Buchanan RB, Lewington VJ, McEwan AJ, Macleod PM, Zivanovic $\mathrm{MH}$ : Strontium-89 chloride for pain palliation in prostatic skeletal malignancy. Br J Radiol 1991;64:816822.

7 Robinson RG, Spicer JA, Preston DF, Wegst AV, Martin NL: Treatment of metastastic bone pain with strontium-89. Nucl Med Biol 1987; 14:219-222.

8 Maxon HR, Deutsch EA, Thomas SR, Lisbon K, Lukes SJ, Williams CC, Ali S: Re-186 [Sn] HEDP for treatment of multiple metastatic foci in bone: Human biodistribution and dosimetric studies. Radiology 1988;166:501-507.

9 Maxon HR, Schroder LE, Thomas SR, et al.: Re-186 [Sn] HEDP for treatment of painful osseous metastases: Initial clinical experience in 20 patients with hormone-resistant prostate cancer. Radiology 1990; 176:155-159.
10 Maxon HR, Schroder LE, Hertzberg VS, Thomas SR, et al: Re-186 [Sn] HEDP for treatment of painful osseous metastases: Results of a double-blind crossover comparison with placebo. JNM 1991;32:1877-1881.

11 Zonnenberg BA, de Klerks JMH, et al: Re-186 HEDP for treatment of patient bone metastases in patients with metastatic prostate or breast cancer: Preliminary results. JNM 1991;32:1082.

12 deClerk JM, van het Schip AD, Zonnenberg BA, van Dijk A, Stokkel MP, Han SH, Blijham GH, Van Rijk PP: Evaluation of thrombocytopenia in patients treated with Re186 HEDP: Guidelines for individual dosage recommendations. JNM 1994;35:1423-1428.

13 Limourise G, Shukla S, et al: Rhenium-186-HEDP palliative treatment in disseminated bone metastases due to prostate cancer. Anticancer Res 1997;17:1690-1704.

14 Schoeneich G, Palmedo H, DierkeDzierzon C, Muller SC, Bier Sack HJ: Rhenium-186 HEDP: Palliative radionuclide therapy of painful bone metastases. Scand J Urol Nephrol 1997;31:445-448. 